\title{
Relative stability enhancement for brushed DC motor using a PLL interfaced with LabVIEW
}

\author{
Mostafa Mahmoud, Ahmed El-Biomey, El-Sayed Soliman Ahmed
}

Department of Electrical Engineering, Al-Azhar University, Egypt

\begin{tabular}{|c|c|}
\hline Article Info & ABSTRACT \\
\hline Article history: & This work presents a fast response and stable computer based a brushed DC \\
\hline Received Jul 14, 2019 & $\begin{array}{l}\text { motor speed controller. The controller configured of gate drive circuits for } \mathrm{H}- \\
\text { Bridge accompanied with data acquisition unit DAO- } 6211 \text {. These gate drive }\end{array}$ \\
\hline Revised Nov 8, 2019 & circuits include, phase comparator, current booster and wave forms cleaning \\
\hline Accepted Feb 12, 2020 & circuits. An optical encoder is used for motor speed to frequency conversion. \\
\hline Keywords: & $\begin{array}{l}\text { (motor speed) with a reference frequency (desired speed). The obtained } \\
\text { phase difference (error) is used to allocate the suitable PWM duty cycles. An }\end{array}$ \\
\hline DAQ-6211 & H-Bridge BJT switches driven by PWM is interfaced with the motor. The \\
\hline DC motor & DAQ-6211 to be interfaced with the LabVIEW software Package. This \\
\hline H-Bridge & allows monitoring and storing the different measured data of this platform. \\
\hline LabVIEW & The system relative stability is determined and examined based on the Bode \\
\hline Phase margin & plot analysis and design. Then the relative stability criterion (Phase Margin) \\
\hline PLL & is measured the closed-loop stability of the system. This system considers the \\
\hline PWM & fast feedback response with indication of its stability state as well as the \\
\hline Relative stability & $\begin{array}{l}\text { stable wide dynamic range. It compensates the changes in system parameters } \\
\text { due to the environmental effects and other disturbances. }\end{array}$ \\
\hline
\end{tabular}

This is an open access article under the CC BY-SA license.

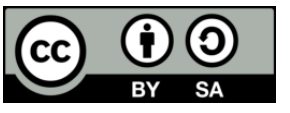

\section{Corresponding Author:}

Mostafa Mahmoud, Department of Electrical Engineering, Faculty of Engineering, Al-Azhar University, Egypt.

Email: mostphemto@gmail.com

\section{INTRODUCTION}

The DC motors have been popular in the industry control area for a long time, because they have many good characteristics, for example: high start torque, fast response performance, easier to be linear control [1]. The different control approach depends on the different performance of motors. The DC motor control is then riper than other kinds of motors no matter in the theoretic study or in the research and development of the application technology. However, the technique of instrument design also moves forward the times of "virtual instrument", not only the designing time is shortened, but also the designing space is more elastic extension [2].

Usually control system does not remain constant throughout its life cycle, so there are always changes in system parameters because of environmental effects and other perturbations and disturbances. These changes and affections are called parameter variations (gain and stability, temperature, supply voltage variations and/or external disturbances) where can be studied using mathematical and physical term expressions to illustrate entire control system change. The more keeping prosperities control system with entire changes the lesser sensitivity of control system $[1,3]$. 
This paper designs a control circuit to supervise and control the speed response of the DC motor with the virtual instrument graphic monitor software LabVIEW [4]. To control the speed and display the changes of rotational speed of the motor with assessment relative stability [17] by instantaneous monitoring phase difference angle $(\Phi)$ as the phase shift between desired and actual signals on PLL output, the better response of the system can be achieved by using the NI USB-6211 data acquisition (DAQ) [1, 5] that will read the data of the control circuit for transmitting the signal using in real time to PC. This does not require transfer functions, just experimental frequency response data of the (stable) open-loop system are necessary to judge the closed-loop stability $[6,7]$. Because the DAQ card has the capability of the data storage, calculating, analysis, Analog to Digital Converter (ADC) and DAC conversion [19]

\section{SYSTEM DESCRIPTION}

The system configured of a permanent magnet DC motor, DC power supply, photo electric encoder B83609, motor control board, DAQ card NI USB-6211 accompanied with the NI-LabVIEW package [13] as shown in Figure 1. It is described and explained briefly as follows:

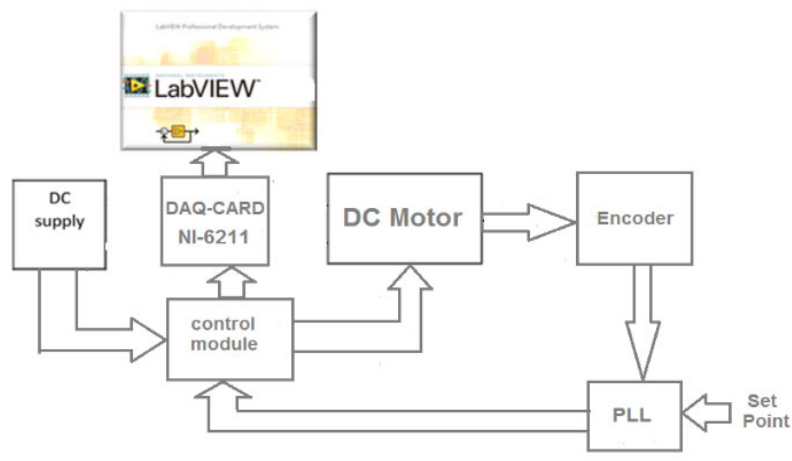

Figure 1. Block diagram of the system

\subsection{Hardware implementation}

This circuit consists of phase locked loop (PLL - CD4046), passive low pass filter (LPF) [8], current amplifier, (regulator LM7805) and (Schmitt trigger 74HC14) as shown in Figure 2.

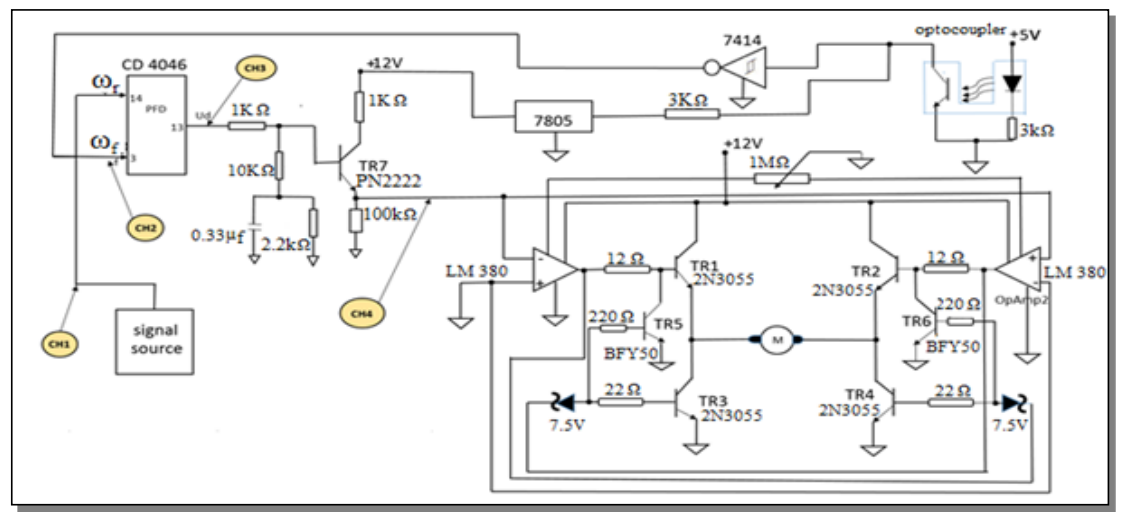

Figure 2. Voltage control circuit of permanent magnet brushed DC motor

The system operation includes both hardware and software modules. Using the LabVIEW program, the system allows the user to monitor the actual motor speed in addition to take direct action when 
the desired speed is out of the control range. This is accomplished with sampling rate of $2.5 \mathrm{kHz}$ for each of the four channels of the developed system [20]. The speed error leads to the average voltage adjustment which will be applied to the driver of the motor after its filtering and amplification. The DC motor speed is measured using (DAS) kit for the control system. The system master clock is internally generated in the PLL. This PLL (CD4046) receives both the actual and the reference speeds. The PLL average voltage error is smoothed and applied to motor drive circuits. Furthermore, the optimized LPF of an adjustable cut off frequency that is according to the selected reference frequency makes two individual functions. The first function is required for noise immunity and the second is working as a lead/lag compensator [23]. The LPF is considered as essential stability issue and used for system final tuning [11]. For good driving of the motor, single (2N2222) current booster has been used to reinforce the signal after noise rejection. Quad chopper of four transistors $(2 \mathrm{~N} 3055)$ is used to provide the rating current which is suitable to the DC motor and speed redirection. On the other hand, the developed LabVIEW modules are used for monitoring the speed, stability, and time response [21].

\subsection{Software Implementation}

The software of this work is configured of the following modules:

\subsubsection{LabVIEW Programs}

The LabVIEW is the most dominant package used for creating, testing and measurement, of the equid data acquisition systems. The LabVIEW systems are broadly classified into, monitoring, logging, and interactive or smart systems [12]. The control system of this work monitors the DC motor speed using the LabVIEW program virtual instruments $\left(\mathrm{VI}_{\mathrm{S}}\right)$ and reads the actual motor feedback and the reference speeds [10]. The reading is performed as RPM and the analogue voltage output of the system in four test points (reference signal, feedback signal, PLL output, current amplifier output) as shown in Figure 2. The front panel and block diagram compile of LabVIEW on PC under windows 8.1 are showing in Figure 3 and Figure 4.

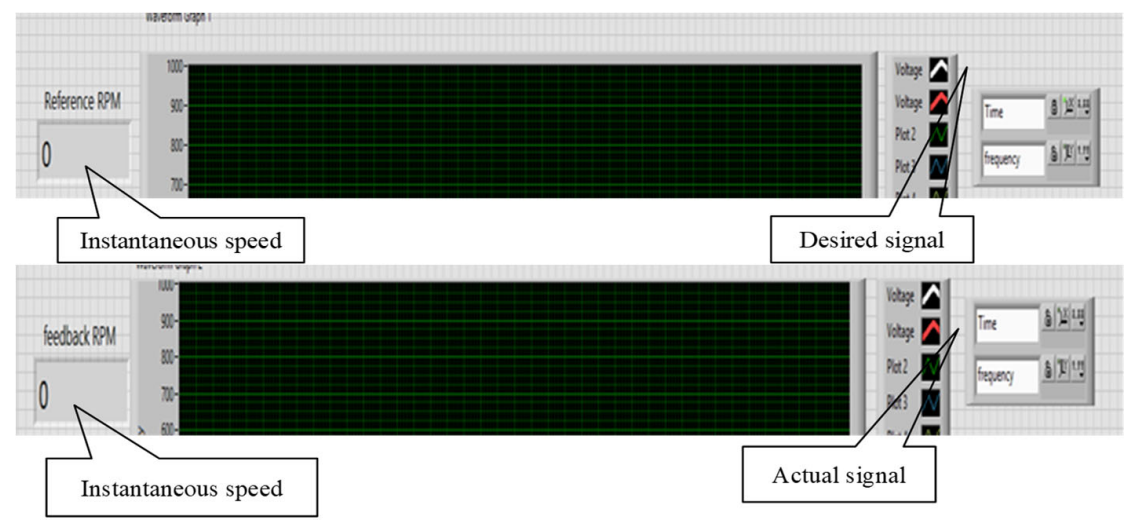

Figure 3. Front panel of the actual and reference speeds with time
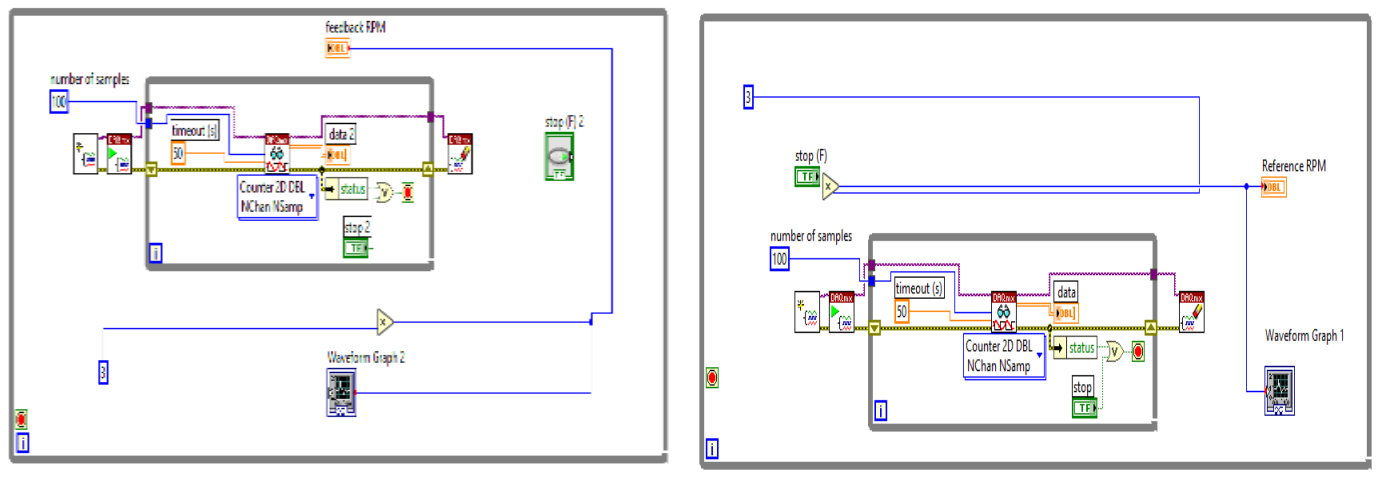

Figure 4. Block diagram of actual and reference speed with time

Relative stability enhancement for brushed DC motor using a PLL interfaced... (Mostafa.Mahmoud) 


\subsection{Flowchart of The Process}

The System Algorithm Flowchart of The Processis shown in Figure 5.
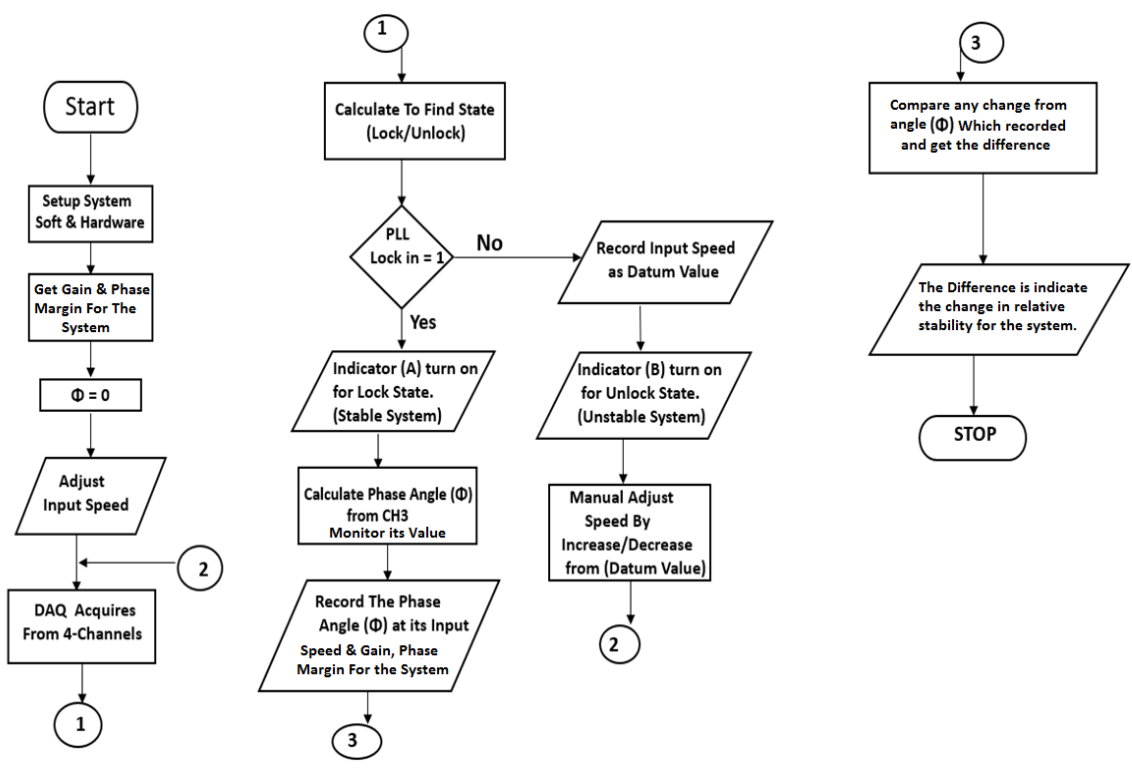

Figure 5. the system algorithm

\section{EXPERIMENTAL RESULTS}

The practical system parameters are used for the system relative stability evolution $[16,18]$. The system was built and tested using a DC motor with speed of $1200 \mathrm{rpm}$ and voltage 12 Volt and current 0.8 Ampere. The rotary encoder has 20 pulses per revolution (ppr). The range of speed control is from $40 \mathrm{rpm}$ to $600 \mathrm{rpm}$ Thus, the system block diagram and its gain $(\mathrm{K}=1.1)$ is shown in Figure 6 , thus transfer function of loop transmission with VI LabVIEW program code as in Figure 7.

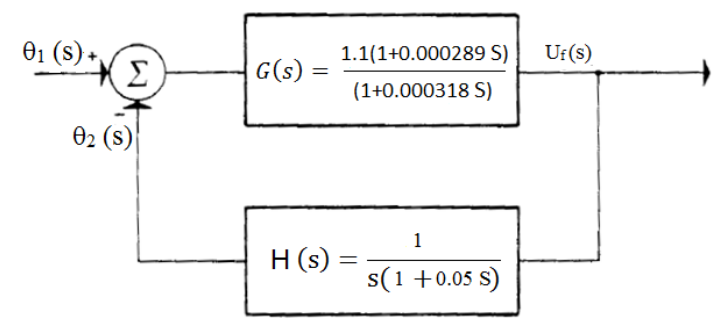

Figure 6 . The condensed mathematical model of the system

The loop transmission state of the system at certain load:

$$
\mathrm{G}(\mathrm{S}) \mathrm{H}(\mathrm{S})=\frac{1.1+0.0003179 \mathrm{~S}}{0.0000159 \mathrm{~S}^{3}+0.05 \mathrm{~S}^{2}+\mathrm{S}}
$$




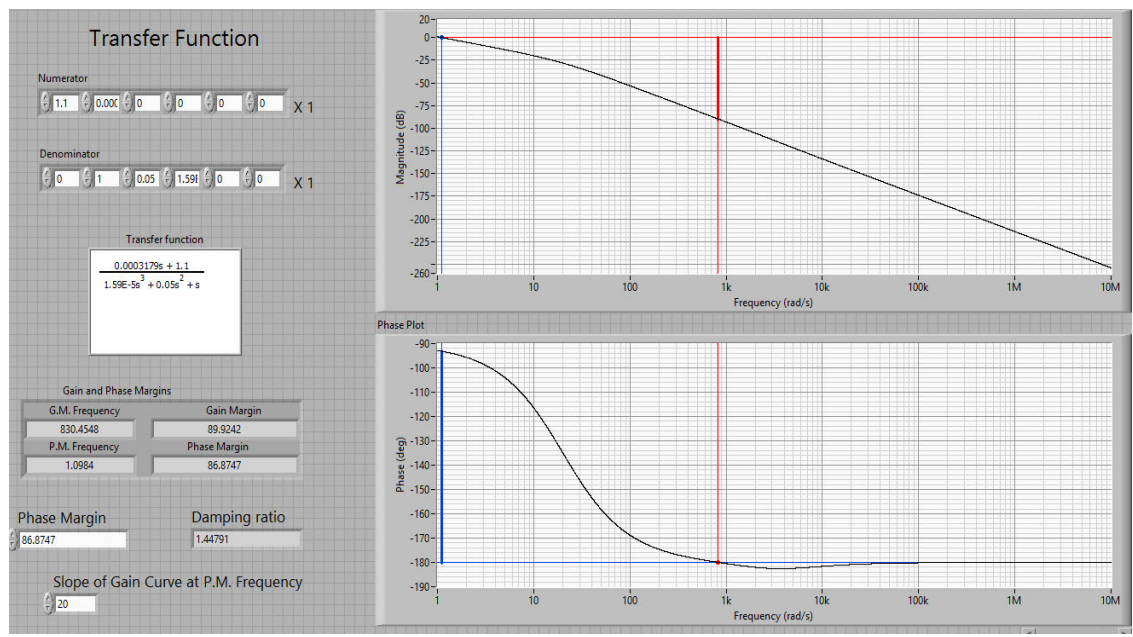

Figure 7. LabVIEW control system VI program code (Bode Plot)

\subsection{Experimental results of the PLL.}

The core of the system controller is the PLL designed to receive both the reference (desired) frequency and the feedback frequency that corresponding to the actual motor speed [24, 25]. An encoder has been coupled with the motor shaft in order to converge the speed to frequency. The PLL receives, both the motor actual and the reference frequencies [14]. According to the phase error of these two frequencies, the PLL provides a suitable duty cycle for driving the DC motor [15]. The variations in the PLL output due to the PLL input phase difference are displayed in Figure 8.

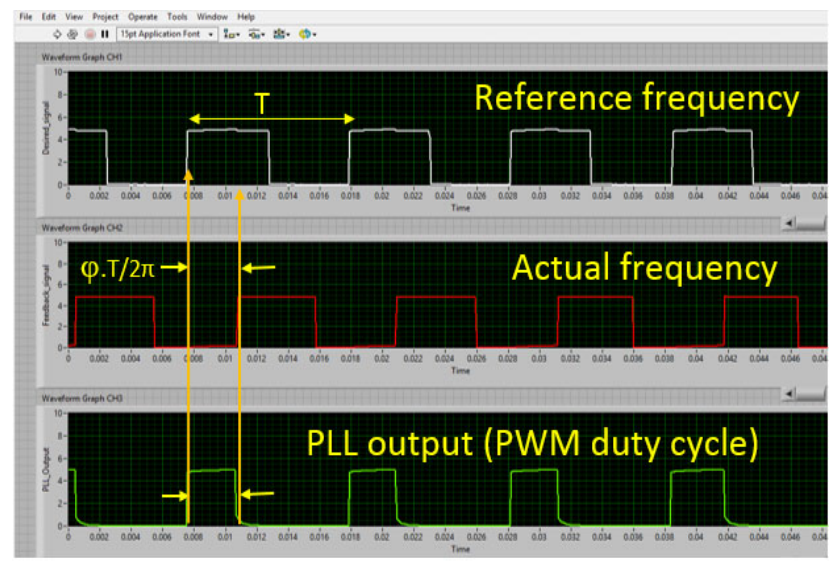

Figure 8. Reference frequency, Actual frequency, PLL output on LabVIEW software design program (VI).

The following figures are the experimental comparison explanation cases at different speeds related to the control circuit to follow up or monitoring it using four measuring points on circuit to be sure that the dynamic behavior of the control circuit of the system is in the normal case. There are four points pertaining to four channels on DAQ ( $\mathrm{CH} 1, \mathrm{CH} 2, \mathrm{CH} 3, \mathrm{CH} 4)$ as demonstrated in Figure 9 and Figure 10. All these channels are recorded simultaneously on DAQ channels (AI0, AI1, AI2, A3). The channel CH1 assign to Reference signal (white color), $\mathrm{CH} 2$ to Feedback signal (red color), $\mathrm{CH} 3$ to comparator out from PLL (green color), CH4 to PWM input signal (blue color). 


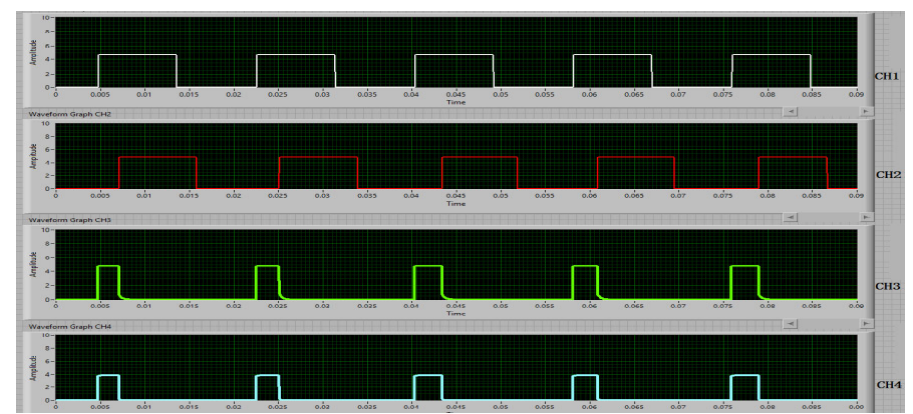

Figure 9. $\mathrm{CH} 1, \mathrm{CH} 2, \mathrm{CH} 3, \mathrm{CH} 4$ simultaneously at constant speed $168 \mathrm{rpm}$ with fixed load of $150 \mathrm{gm}$ for the DC motor.

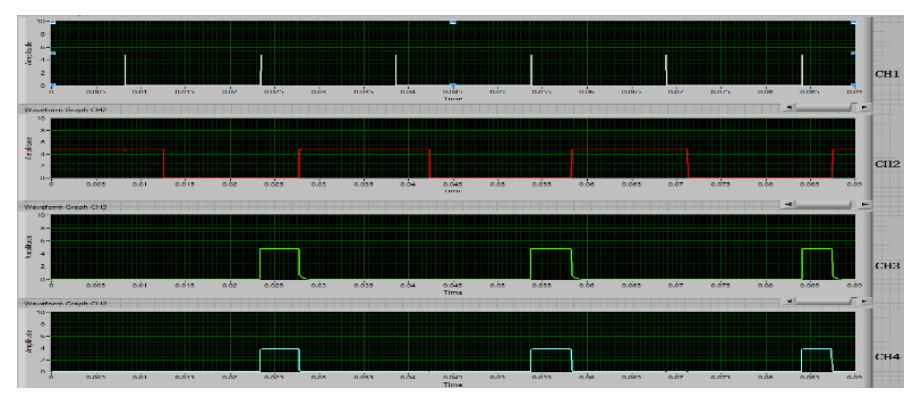

Figure.10. $\mathrm{CH} 1, \mathrm{CH} 2, \mathrm{CH} 3, \mathrm{CH} 4$ simultaneously at desired speed $99 \mathrm{rpm}$ With fixed load of $150 \mathrm{~g}$ for the DC motor.

\subsection{System response for different loads}

The LabVIEW software modules are the speed control, stability, and time response on the system monitors [22]. Some of the PLL output-controlled phase difference angle ( $\boldsymbol{\Phi})$ that are corresponding to the different loads are listed in Table 1.

Table 1. PLL output phase angle vs different load and speeds

\begin{tabular}{|c|c|c|c|c|c|}
\hline $\begin{array}{l}\text { Weight }(\mathrm{gm}) \\
\text { (Load) }\end{array}$ & $\begin{array}{c}53.7 \mathrm{~Hz} \\
\text { Phase angle (Degree) } \\
\Phi\end{array}$ & $\begin{array}{c}97.5 \mathrm{~Hz} \\
\text { Phase angle } \\
\text { (Degree) } \Phi\end{array}$ & $\begin{array}{c}126 \mathrm{~Hz} \\
\text { Phase angle } \\
\text { (Degree) } \Phi\end{array}$ & $\begin{array}{c}155 \mathrm{~Hz} \\
\text { Phase angle } \\
\text { (Degree) } \Phi\end{array}$ & $\begin{array}{c}202 \mathrm{~Hz} \\
\text { Phase angle } \\
\text { (Degree) } \Phi\end{array}$ \\
\hline 0 & $\begin{array}{c}\text { Lockout / unstable } \\
\text { system }\end{array}$ & $56.2^{\circ}$ & $72.72^{\circ}$ & $111.6^{\circ}$ & $145.4^{\circ}$ \\
\hline 100 & $\begin{array}{c}\text { Lockout / unstable } \\
\text { system }\end{array}$ & $73.8^{\circ}$ & $90.7^{\circ}$ & $122.8^{\circ}$ & $159.8^{\circ}$ \\
\hline 150 & $48.2^{\circ}$ & $105.1^{\circ}$ & $127.1^{\circ}$ & $167.4^{\circ}$ & $\begin{array}{c}\text { Lockout / unstable } \\
\text { system }\end{array}$ \\
\hline 280 & $67.7^{\circ}$ & $122.8^{\circ}$ & $176.8^{\circ}$ & $195.5^{\circ}$ & $\begin{array}{c}\text { Lockout / unstable } \\
\text { system }\end{array}$ \\
\hline 535 & $91.8^{\circ}$ & $140^{\circ}$ & $222.1^{\circ}$ & $\begin{array}{c}\text { Lockout / unstable } \\
\text { system }\end{array}$ & $\begin{array}{c}\text { Lockout / unstable } \\
\text { system }\end{array}$ \\
\hline
\end{tabular}

The motor operation modes according to the external load can be arranged through five different motor speed [9], which are:

- $\quad 161 \mathrm{RPM} / 53.7 \mathrm{~Hz}$

For no load up to the $100 \mathrm{gm}$, the motor is still lockout and no effective duty cycle of the PLL that leads the motor speed to be lock-in. For a load of $150 \mathrm{gm}$ the motor starts the lock-in (stable operational range) and keep constant speed up to around $535 \mathrm{gm}$ as shown in Figure 11 . One can see that the duties $(2.5 \mathrm{~ms}, 3.5 \mathrm{~ms}$ and $4.75 \mathrm{~ms}$ ) cycles change according to the given loads $150 \mathrm{gm}, 280 \mathrm{gm}$ and $535 \mathrm{gm}$ respectively.

- $465 \mathrm{RPM} / 155 \mathrm{~Hz}$

Int J Pow Elec \& Dri Syst, Vol. 11, No. 2, June 2020 : 735 - 742 
Locked-in motor speed range is located start from the no load condition, up to $280 \mathrm{gm}$ with constant speed. The motor had locked-out at load of $535 \mathrm{gm}$ resulting in an unstable operation as shown in fig 12 . However, the duties $2 \mathrm{~ms}, 2.2 \mathrm{~ms}, 3 \mathrm{~ms}, 3.5 \mathrm{~ms}$ cycle are due to the given no load, $100 \mathrm{gm}, 150 \mathrm{gm}, 280 \mathrm{gm}$ respectively, the load $535 \mathrm{gm}$ resulting in unknown duty outgoing the stable operational zone.

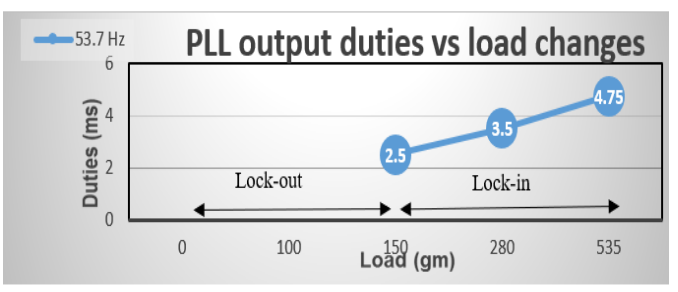

Figure 11. Duty cycle vs motor Load (161 rpm)

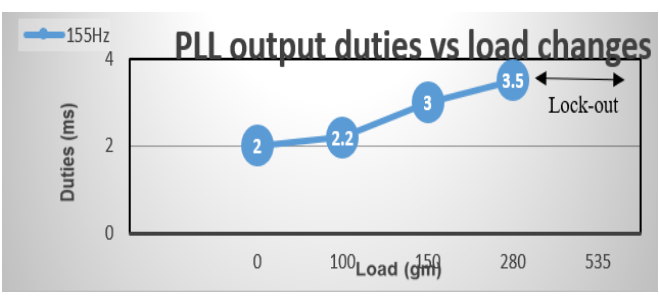

Figure 12. Duty Cycle vs Motor load (465 rpm)

\section{CONCLUSION}

Digital control for the DC motor based on computer system has been designed, experimentally implemented and elaborated. The PLL is used as phase and frequency comparator for measuring the speed drift w.r.t the desired reference speed. Simple and easy to use LabVIEW were has been used to achieve the suggested approach of the DC motor speed control. The system has been developed to include the graphical user interface using LabVIEW software as well as the DAQ-6211 module of national instruments. The system shows that the widest stable range is located at the measured speed range of ( $290 \mathrm{rpm}$ to $378 \mathrm{rpm}$ ) for the all selected loads ( $100 \mathrm{~g}$ up to $535 \mathrm{~g}$ in 5 steps). The Bode plot of the system loop transmission shows that the system relative stability depends on both the load and the phase margin.

\section{REFERENCES}

[1] Rozenwasser, E. and Yusupov, R., "Sensitivity of automatic control systems," CRC press, 1999.

[2] LabVIEW Basics, I.I., "Development course manual," National Instruments Corporation, Austin, Texas, 2003.

[3] Somerville, J.W. and Macia, N.F., "A feedback control system for engineering technology laboratory courses," 2001.

[4] Raj Thummar, Kalpesh Chudasama, Raj Koshiya and Dilp Odedara, "Monitoring of Electric industrial process parameters using LabVIEW," International Journal of Current Engineering and Technology, vol. 6, no.6, pp. 2126-2129, Dec 2016.

[5] Shenton, A.T. and Shafiei, Z., "Relative stability for control systems with adjustable parameters," Journal of Guidance, Control, and Dynamics, vol. 17, no. 2, pp. 304-310, 1994.

[6] Vikhe, P., Punjabi, N. and Kadu, C., "Real Time DC Motor Speed Control using PID Controller in LabVIEW," International Journal of Advanced Research in Electrical, Electronics and Instrumentation Engineering, vol. 3, no. 9, pp. 12162-12167, 2014.

[7] Singh, B., Payasi, R.P., Verma, K.S., Kumar, V. and Gangwar, S., 2013, "Design of Controllers PD, PI \& PID for Speed Control of DC Motor Using IGBT Based Chopper", German Journal of Renewable and Sustainable Energy Research (GJRSER), 1(1), pp. 29-49.

[8] Memon, A.P., Khan, W.A., Memon, R.H. and Akhund, A.A., "Laboratory studies of speed control of DC shunt motor and the analysis of parameters estimation," International Journal of Emerging Trends in Electrical and Electronics (IJETEE), vol. 9, no. 1, pp. 23-29, 2013.

[9] Angalaeswari, S., Kumar, A., Kumar, D. and Bhadoriya, S., "Speed control of permanent magnet (PM) DC motor using Arduino and LabVIEW," Computational Intelligence and Computing Research (ICCIC), 2016 IEEE International Conference on, IEEE, pp. 1-6, 2016.

[10] Bharatiraja, C., Munda, J.L., Vaghasia, I., Valiveti, R. and Manasa, P., "Low cost real time centralized speed control of DC motor using lab view-NI USB 6008," International Journal of Power Electronics and Drive Systems (IJPEDS), vol. 3, no. 3, pp. 656-664, 2016.

[11] Banerjee, D., 2006, "PLL performance, simulation and design" DogEar Publishing.

[12] Dewangan, A.K., Chakraborty, N., Shukla, S. and Yadu, V., "PWM based automatic closed loop speed control of DC motor," International Journal of Engineering Trends and Technology, vol. 3, no. 2, pp. 110-112, 2012.

[13] Paraskevopoulos, P.N., "Modern control engineering," CRC Press, 2017.

[14] Gowthaman, E. and Balaji, C.D., "Self-tuned PID based speed control of PMDC drive," Automation, Computing, Communication, Control and Compressed Sensing (iMac4s)", International Multi-Conference on, IEEE, pp. 686-692, 2013. 
[15] Sahputro, S.D., Fadilah, F., Wicaksono, N.A. and Yusivar, F., "Design and implementation of adaptive PID controller for speed control of DC motor," In 2017 15th International Conference on Quality in Research (QiR): International Symposium on Electrical and Computer Engineering, IEEE, pp. 179-183, 2017.

[16] Sarhan, H., "A software-based gain scheduling of PID Controller," International Journal of Instrumentation and Control Systems, vol. 4, no. 3, pp.1-10, 2014.

[17] Angalaeswari, S., Kumar, A., Kumar, D. and Bhadoriya, S., "Speed control of permanent magnet (PM) DC motor using Arduino and LabVIEW," Computational Intelligence and Computing Research (ICCIC), IEEE International Conference on, IEEE, pp. 1-6, 2016.

[18] Patton, J.L., Lee, W.A. and Pai, Y.C., "Relative stability improves with experience in a, dynamic standing task," Experimental Brain Research, vol. 135, no. 1, pp.117-126, 2000.

[19] Barth, E.J., Zhang, J. and Goldfarb, M., "Control design for relative stability in a PWM-controlled pneumatic system," Transactions-American Society of Mechanical Engineers Journal of Dynamic Systems Measurement and Control, vol. 125, no. 3, pp. 504-508, 2003.

[20] Dorf, R.C. and Bishop, R.H., "Modern control systems," Pearson, 2011.

[21] Grantham, W.J. and Vincent, T.L., "Modern Control Systems Analysis and Design: Analysis and Design," John Wiley \& Sons, Inc., 1993.

[22] Fagiri, M.A. and Nerma, M.H., "Effect of proportional integral controller in the stability of direct current motor," International Journal in IT \& Engineering, vol. 3, no. 3, pp. 210-220, 2015.

[23] Dubey, S. and Srivastava, S.K., "A PID controlled real time analysis of DC motor," International Journal of Innovative Research in Computer and Communication Engineering, vol. 1, no. 8, pp. 1965-1973, 2013.

[24] Trinh, H.H. and Le, T.D., "DC Model-based IMC Method for Brushless DC Motor Speed Control," Journal of Automation and Control Engineering, vol. 4, no. 2, pp. 104-110, 2016.

[25] Theraja, B.L. and Theraja, A.K., "Electrical technology," S. chand New Delhi, pp .926, 2002.

Int J Pow Elec \& Dri Syst, Vol. 11, No. 2, June 2020 : 735 - 742 